Renata M. L. Fujita, Lara L. B. de Senne *

\title{
Contribuições metodológicas de processos colaborativos e participativos do design para a economia solidária
}

Renata M. L. Fujita é Doutoranda do Programa de Pós-Graduação em Design (FAU-USP); Mestre (2017) pelo Programa de Pós-Graduação em Têxtil e Moda (EACH-USP); pós-graduada (2012) em Moda e Criação pela Faculdade Santa Marcelina (Lato Sensu) e graduada em Negócios da Moda na Universidade Anhembi Morumbi (2010). Atuou profissionalmente como produtora executiva e gerente de projetos especiais em empresa de representação e consultoria, realizando projetos a fim de promover destinos turísticos em conjunto com a moda; agente comercial na indústria têxtil (INTESA), assistente de compras na M5 Têxtil e produtora de moda em assessoria de comunicação (Maquinário).

<mayumi_lf@hotmail.com>

ORCID: 0000-0002-6481-0120
Resumo Contextualizamos o design como uma área cujos conhecimentos práticos e científicos demonstram capacidade de propor inovações ao sistema de produção de bens de consumo, o qual apresenta questões éticas e ambientais que afetam profundamente nossa sociedade. Neste sistema, identificamos os empreendimentos da economia solidária como uma interessante alternativa econômica, cultural e ambiental, devido a seus valores de autogestão, cooperação e solidariedade, e sua proposta de produção sustentável. Desta forma, buscou-se conceituar, por meio da revisão de literatura as abordagens de Design Colaborativo, Design participativo e Design Thinking, com o propósito de examinar caminhos para a contribuição do design nas atividades produtivas de empreendimentos econômicos solidários e buscar compreender qual seria o papel do design neste contexto.

Palavras chave Design colaborativo, Design participativo, Design Thinking, Economia Solidária. 
Lara L. B. de Senne é professora doutora do grupo de disciplinas de desenho industrial (GDDI) do Departamento de Projeto da Faculdade de Arquitetura e Urbanismo da Universidade de São Paulo (FAU-USP). Arquiteta e Urbanista formada pela Escola de Engenharia de São Carlos da Universidade de São Paulo (EESC-USP) em 1999. Mestre em Tecnologia do Ambiente Construído pela EESC-USP em 2003. Doutora em Arquitetura e Design pela Faculdade de Arquitetura e Urbanismo da Universidade de São Paulo (FAU-USP). É autora do livro "Design sem fronteiras: a relação entre o nomadismo e a sustentabilidade", publicado pela Edusp e Fapesp em 2012, o qual recebeu o 1ํo lugar no Prêmio do Museu da Casa Brasileira em 2009. Esse mesmo livro recebeu o $3^{\circ} \mathrm{lu}$ gar do Prêmio Jabuti 2013 na Categoria Arquitetura e Urbanismo. Atualmente é a coordenadora do grupo NOAH- Núcleo Habitat sem Fronteiras, onde desenvolve e orienta pesquisas sobre Design para situações emergenciais na FAU-USP.

<barbosall@usp.br>

ORCID: 0000-0002-8636-2904

\section{Methodological contributions of collaborative and participatory of design proces- ses for the solidarity economy}

Abstract We review design as an area whose practical and scientific knowledge demonstrates capacity for innovation in the consumer goods production system, which presents ethical and environmental issues that profoundly affect our society. In this system, we identify solidarity economy's enterprises as an interesting economic, cultural and environmental alternative, due to its values of self- management, cooperation and solidarity, and its proposal for sustainable production. In this way, we tried to conceptualize, through the literature review, the approaches of Collaborative Design, Participatory Design and Design Thinking, with the purpose of investigating paths for the contribution of design in the productive activities of solidary economic enterprises and to understand what would be the role of design in this context.

Keywords Collaborative Design, Participatory Design, Design Thinking, Solidarity Economy. 


\section{Introdução}

Ao longo da última década, observamos maiores discussões que relacionam economia, sociedade e meio ambiente em um contexto de transformação global. Crises econômicas e ambientais evidenciaram questões complexas do nosso contemporâneo, como o impacto ambiental das atividades humanas; esgotamento dos recursos naturais; a precarização da mão de obra; processos de migração; grupos sociais marginalizados; entre diversas outras, cujas investigações envolvem as mais diversas disciplinas.

Nesta conjuntura a economia solidária se apresenta como uma prática alternativa de produção, comercialização, finanças e consumo, que propõe valores humanos e ambientais em sua conduta, como possibilidade de desenvolvimento sustentável, sob a luz da autogestão, da cooperação e da solidariedade.

Este artigo busca relacionar como o conjunto específico de habilidades e competências do design pode oferecer perspectivas de desenvolvimento no âmbito da economia solidária. Desta forma, contextualizou-se a caracterização da economia solidária, bem como os conceitos de design participativo, design colaborativo e design thinking por meio da revisão de literatura.

\section{Conceitos e práticas da economia Solidária}

Segundo Laville e Gaiger (2009, p.163), a economia solidária se desenvolve mediante a "longa história associativa dos trabalhadores, iniciada no começo do século XIX", portanto, esta organização está estritamente conectada aos valores humanos e direitos trabalhistas e suas atividades são frequentemente referenciadas como alternativas, uma vez em que "dada a ruptura que introduzem nas relações de produção capitalistas, elas representariam a emergência de um novo modo de organização do trabalho e das atividades econômicas em geral" (GAIGER, 2003, p.18). Fujita (2017) destaca a autogestão, a solidariedade e a cooperação como conceitos norteadores das atividades da economia solidária.

Pressupõe-se na economia solidária que todas suas formas organizacionais devem ser geridas democraticamente. A cooperativa, vista por Paul Singer (2002) como o protótipo de empresa solidária, não tem fins lucrativos, apesar de ter fins econômicos, ela não é caracterizada pelo acúmulo de capital, mas sim como meio de sustento de seus sócios. Não deve existir uma relação de dono e empregado, nos empreendimentos todos são sócios, todos têm direito a um voto e dividem os ganhos igualmente. Esta prática, denominada de autogestão, exige que os sócios sejam e se mantenham sempre informados sobre as questões do empreendimento. Singer (2002, p.21) pondera que a autogestão pode se apresentar como uma dificuldade por conta da "insuficiente formação democrática dos sócios" ou a "lei do menor esforço", porém, ressalta que "tem como mérito principal não a eficiência econômica (necessária em si), mas o desenvolvimento humano que proporciona aos praticantes". 
As relações de igualdade devem ser cultivadas entre os sócios, uma vez que, apenas desta forma se realiza a solidariedade na economia. Laville (2009, p.310) discute a existência de dois tipos de solidariedade: a solidariedade filantrópica e a solidariedade como princípio de democratização societária. A primeira surge de uma necessidade assistencialista e consiste em uma ação paliativa, enquanto a segunda é sustentada "tanto na ajuda mútua, como na expressão reivindicativa, tangendo, ao mesmo tempo, à auto-organização e ao movimento social".

A concepção de solidariedade em um empreendimento econômico é contrária à determinação contemporânea de competitividade aplicada a todos os âmbitos no mercado capitalista. Singer (2002) defende que uma economia que prioriza a solidariedade acima da competitividade produz menos desigualdades sociais:

\footnotetext{
O programa de economia solidária se fundamenta na tese de que as contradições do capitalismo criam oportunidades de desenvolvimento de organizações econômicas cuja lógica é oposta à do modo de produção dominante. O avanço da economia solidária não prescinde inteiramente do apoio do Estado e do fundo público (...) Mas, para uma ampla faixa da população, construir uma economia solidária depende primordialmente dela mesma, de sua disposição de aprender e experimentar, de sua adesão aos princípios de solidariedade, da igualdade e da democracia e de sua disposição de seguir estes princípios na vida cotidiana etc (SINGER, 2002, p.112).
}

A cooperação pode ser definida, de um modo limitado, como a forma em que as ações coletivas são conduzidas a fim de alcançar um objetivo comum. Esta é uma relação própria dos seres humanos que, historicamente foi empregada como uma forma de sobrevivência de grupos e sociedades (JESUS e TIRIBA, 2009). Assim como a solidariedade, a cooperação acaba por ser minimizada tanto no relacionamento entre empresas quanto entre funcionários em favor da competitividade e hierarquia. Isso resulta em um paradoxo, uma vez em que a cooperação de muitos supera a produtividade individual (JESUS e TIRIBA, 2009; SINGER, 2002).

Podemos destacar também outros princípios os quais definem as condutas dos empreendimentos econômicos solidários que são listados no Projeto de Lei 4685/2012: adesão livre e voluntária; desenvolvimento das atividades de forma ambientalmente sustentável; busca da inserção comunitária, com a adoção de práticas democráticas e de cidadania; prática de preços justos; respeito às diferenças e promoção da equidade de direitos de gênero, geração, raça, etnia, orientação sexual.

No Brasil, a economia solidária passa a ter maior representatividade a partir da década de 1980, quando houve um esfriamento da economia e a crise do desemprego. Isso pode ser percebido novamente, com maior intensidade, com a abertura do mercado brasileiro na década de 1990. Durante este período, surgem entidades representativas da economia solidária, como a Associação Nacional de Trabalhadores e Empresas de Autogestão 
(ANTEAG) e a Unisol Brasil, assim como pesquisas acadêmicas que buscam investigar as atividades de sobrevivência de uma parcela da população que busca uma forma alternativa de trabalho e renda.

A partir de seus princípios de respeito ao trabalhador e ao meio ambiente, a economia solidária se mostra uma alternativa econômica e produtiva pertinente à medida que caminha na contramão de um mercado voltado ao consumismo que, por sua vez, atua com uma produção cada vez mais acelerada, com a obsolescência programada de produtos, a precarização da mão de obra e as implicações que tais atividades resultam para a sociedade.

Considerando a prática da economia solidária como um caminho possível para o desenvolvimento sustentável, devemos refletir sobre o papel do design neste contexto. Manzini (2008, p. 25) pondera que, para a nossa sociedade alcançar o desenvolvimento sustentável, será necessário um longo período de transição em que novas ideias devem ser geradas por meio de um extenso questionamento acerca do sistema vigente. $O$ autor avalia que a posição de ação do designer neste processo estaria baseada em sua "habilidade em definir objetivos que combinem suas próprias necessidades e exigências com os critérios da sustentabilidade que estão gradualmente vindo à tona".

Podemos ponderar que a experiência da economia solidária caracteriza um esforço rumo ao período de transição mencionado por Manzini. Ela encontra-se em um cenário complexo de contraposição, no sentido de que ao mesmo tempo em que sua prática é regida por valores distintos aos da lógica capitalista, inevitavelmente, os empreendimentos econômicos solidários estão inseridos e "competem" no mercado tradicional. Esta contradição intrínseca da economia solidária apresenta-se como um grande obstáculo para seu desenvolvimento, mas também, pode revelar uma oportunidade para o surgimento de ideias e soluções inovadoras no âmbito do design.

Papanek (1995) prevê o futuro do design como uma atividade congregadora de diversas disciplinas, e reafirma sua crença de que a ecologia, seus métodos e ideias, deveriam orientar a formação do designer. 0 autor discorre sobre como o design seria alterado sob a ótica da ecologia:

\footnotetext{
Deveria haver uma ênfase maior na qualidade, durabilidade e perfeição dos produtos criados, à medida que pessoas como os designers compreendam que a obsolescência ou o mau acabamento desperdiçam recursos naturais que não podem ser substituídos, e contribuem para a escassez global. 0 estilo do futuro basear-se-á em produtos que envelheçam graciosamente, $\mathrm{e}$ serão mais atemporais do que as novidades, as tendências e as modas, que mudam rapidamente nos finais do século XX (PAPANEK, 1995, p.52).
}

Os produtos da economia solidária podem transmitir aos consumidores valores de sustentabilidade socioambiental, isto apresenta-se como uma vantagem competitiva no mercado. Todavia, a comunicação de valores éticos e ambientais em um produto, desacompanhada dos atributos descritos por Papanek ou da adequação estética aos desejos e necessidades do 
consumidor, torna a produção solidária demasiadamente relacionada à nichos de mercado de consumo ecológico e solidário.

Compreendemos que, apesar de haver, atualmente, maiores informações sobre a degradação do meio ambiente e questões sociais relacionadas à processos de fabricação, a grande maioria dos consumidores não apresenta como intuito primário de consumo a motivação ecológica ou solidária. Outras motivações se fazem fundamentais para o consumo na sociedade contemporânea, como o fenômeno da moda, estilo de vida, individualidade e construção de identidade, a manutenção e comunicação de um status social, diferenciação e pertencimento, entre muitas outras que constituem o complexo processo de consumo nas sociedades ocidentais (BARBOSA, 2004).

Desta forma, podemos considerar que o êxito comercial da produção solidária esteja apoiado também no desenvolvimento de atributos estéticos que atendam aos desejos do público consumidor. Pantaleão et al. (2016, p.3301) defende a concepção de uma "função estética sustentável", com o intuito de direcionar a sociedade à um consumo "eticamente mais responsável, significativo, e consequentemente mais duradouro".

A adequação estética às demandas do mercado possibilitaria uma maior abrangência de consumidores, isto representaria um fortalecimento econômico dos empreendimentos solidários e aumento da conscientização da população acerca de uma produção sustentável. Neste âmbito, defendemos a atuação do design nesta discussão, uma vez em que "o enfoque integrador de design não exclui a dimensão estética, mas inclui a estética como aspecto constitutivo do uso" (BONSIEPE, 2011, p.231).

\section{Processos colaborativos no design}

O processo de design relaciona as diversas etapas, organizadas sequencialmente e realizadas de forma sistemática, com aplicação de métodos e técnicas, com o objetivo da concretização de um determinado projeto (COELHO, 2008).

Respeitando as normas de condutas autogestionárias da operação econômica solidária, é necessário que a atuação do design também ocorra de maneira democrática e coletiva, com o objetivo de promover a autonomia do empreendimento. Desta forma, buscamos compreender, a partir da literatura analisada, como acontece o processo de design com a participação de designers e não-designers.

$O$ ato coletivo de compartilhamento e criação de conhecimento entre indivíduos em um projeto de design apresenta-se sob diferentes termos na bibliografia analisada, nem sempre com distinções claras, encontramos menções aos termos "Design Participativo", "Design Colaborativo" e "Co-Design". Fez-se necessário, portanto, compreender a utilização dos termos encontrados, quais são suas definições, suas diferenças e contextos. Incluímos neste estudo, também, a abordagem de Design Thinking por sua proposta inclusiva do processo criativo projetual à não-designers. 


\section{Design Participativo}

o design participativo tem suas raízes em movimentos sócio-políticos europeus, principalmente na democratização do trabalho frente a introdução de novas tecnologias na Escandinávia a partir da década de 1970. O ponto de vista inicial desta abordagem é de que as pessoas afetadas pelo design deveriam ter participação em seu processo (EHN, 2008).

Observamos nas descrições acerca do design participativo o objetivo de "alcançar o desafio inalcançável do design de antecipar completamente, ou de prever, o uso antes do próprio uso" (EHN, 2008, p.1), para isso, a participação no design "busca envolver ativamente as pessoas a quem o design está servindo". Simonsen e Robertson (2013) oferecem uma definição sobre como seria o processo de design participativo e a relação entre participantes:

\footnotetext{
Um processo de investigação, compreensão, reflexão, elaboração, desenvolvimento, e apoio da aprendizagem conjunta entre múltiplos participantes durante a "reflexão em ação" coletiva. Os participantes geralmente assumem os dois principais papéis de usuários e designers, onde os designers aspiram aprender a realidade da situação do usuário, enquanto os usuários aspiram articular seus objetivos e adquirir habilidades e conhecimentos para atingi-los (SIMONSEN e ROBERTSON, 2013, p.2).
}

Nesta concepção, entendemos que esta abordagem se beneficia da participação ativa do usuário no processo de design. Já Sanders et. al (2010, p. 195) expandem a delimitação dos não- designers participantes para além de usuários, incluindo stakeholders e outros indivíduos com formações e funções distintas dentro de uma organização (profissionais de marketing, vendas, engenharia, etc.)

Uma interessante perspectiva para esta discussão é a visão de Lee (2015), que situa a participação no âmbito da colaboração quando o espaço abstrato dos especialistas (designers) se reúne com o espaço concreto das pessoas (não-designers). No domínio da colaboração, o design participativo apresenta dois objetivos primordiais: a colaboração, onde o designer toma o papel de facilitador e o não-designer se apresenta como parceiro, e ambos são co-designers em determinado projeto; e a emancipação, onde a função do designer é estimular as capacidades criativas dos participantes.

Entendemos, portanto, que existem níveis diferentes de participação que podem incluir ou não o conceito de colaboração em um processo de design. A não colaboração pode ser definida e antecipada em um processo participativo mediante os objetivos do projeto. A incapacidade de chegar à um estado desejado de colaboração pode ser o resultado de diversos fatores, como a indisposição dos participantes ou a dificuldade em criar um entendimento compartilhado. 


\section{Design Colaborativo/Co-design}

Ao analisar a bibliografia levantada sobre o tema de design colaborativo, encontramos também referências aos termos de co-design e co-criação, utilizados de forma intercambiável.

Sanders e Stappers (2008, p.2) abordam a utilização paralela destes termos e oferecem uma diferenciação entre os conceitos. Os autores posicionam a co-criação como um ato de criatividade coletiva, que é experienciada e realizada em conjunto por um grupo de pessoas. Enquanto definem o co-design como a "criatividade coletiva enquanto aplicada ao longo do processo de design". O co- design seria então, nesta definição, "uma instância específica da co-criação", que se refere à atividade do processo de design.

O termo co-design ou codesign, trata da junção das palavras colaboração e design, portanto são sinônimos para o conceito de design colaborativo, o qual Kleinsmann (2006, p.30) define como um processo onde uma equipe multidisciplinar compartilha seus "conhecimentos tanto sobre o processo de design quanto o conteúdo de design", isto é feito com "o objetivo de criar um conhecimento compartilhado", que é determinado em dois aspectos: a capacidade de "integrar e explorar seus conhecimentos e alcançar um objetivo em comum: o novo produto a ser projetado".

A colaboração no design pode apresentar diferentes configurações: entre designers trabalhando em equipe, onde todos são responsáveis pelo projeto; entre designers que não fazem parte do mesmo grupo, neste caso as interações são informais; entre designers e usuários; entre designers e não-designers. A última configuração citada, a qual é de maior interesse na investigação de processos colaborativos do design na economia solidária, é a que apresenta maior potencial de conflito, por unir indivíduos que terão diferentes experiências anteriores, vocabulários, formas de trabalho, percepções de qualidade, prioridades e restrições, além de distintas representações do conteúdo do processo de design (HEEMAN e VENDRAMINI, 2015; KLEINSMANN, 2006).

A congregação destas diferentes características resulta na dificuldade de comunicação, a qual pode levar à resultados insatisfatórios. A comunicação envolve um emissor e um receptor e é central para a colaboração, pois é desta forma que os participantes compartilham e constroem conhecimento acerca do conteúdo do design, chegam a acordos e tomam decisões em conjunto. No processo projetual, existem diferentes métodos para a comunicação, que incluem descrições verbais, textos, sketches, tabelas, desenhos técnicos, entre outros, que devem ser utilizados mediante as demandas do projeto e dos participantes (CHIU, 2002).

\section{Design Thinking}

O termo design thinking é utilizado no âmbito das pesquisas em design para se referir ao processo cognitivo de um designer. Mais recentemente, na área de gestão estratégica, se refere a uma abordagem para 
resolver problemas e incentivar inovações por meio de técnicas e métodos do design. Para Brown (2010), o ponto de partida do design thinking se encontra nas habilidades que os designers aprenderam ao longo de anos de prática e pesquisa para harmonizar as necessidades humanas e os recursos técnicos disponíveis dentro das delimitações de uma organização específica.

Esta abordagem torna-se interessante, no contexto deste artigo, ao propor o design thinking como um conjunto de ferramentas, práticas e métodos vantajosos tanto para designers quanto para não-designers, pois parte do princípio que todos nós possuímos capacidades intuitivas e criativas aplicáveis para a solução de problemas.

A prática do design parece acontecer, atualmente, cada vez mais em grupos, tornando mais escassa a imagem do criador solitário. Tim Brown (2010) reconhece o valor de uma equipe de design thinkers de diferentes contextos profissionais, ressalta, porém, que é a capacidade de colaboração dos atores que define a interdisciplinaridade do grupo, a qual é fundamental para favorecer as tomadas de decisão e originar um solo fértil para inovações criativas.

A empresa de design IDEO é reconhecida pela difusão de sua metodologia centrada no humano. Seu manual "Human Centered Design: kit de ferramentas" propõe um processo baseado em três fases denominadas HCD (Hear, Create, Deliver). A primeira, denominada "Ouvir", tem como objetivo entender profundamente o problema e o usuário por meio de dados qualitativos obtidos por meio de estudos de caso e observação. A segunda é a etapa "Criar", que busca compreender e sintetizar as informações recolhidas na fase anterior, identificar padrões, definir oportunidades e criar soluções. A terceira fase é "Implementar", aqui, as soluções criadas são modeladas e sua viabilidade é testada.

Outro modelo de processo é explicitado no manual da d.school (Instituto de design Hasso Plattner - Universidade de Stanford) que propõe cinco etapas: (1) Empatia, conhecer o usuário do contexto do projeto; (2) Definição, delimitar claramente o desafio do projeto; (3) Ideias, fase que se concentra na geração de ideias; (4)Protótipos, protótipos das possíveis soluções; (5) Testes, opiniões dos usuários acerca dos protótipos efetuados.

0 processo do design thinking é fundamentalmente exploratório. Sempre ocorrerão novas descobertas ao longo do caminho, que podem acontecer de forma linear, em harmonia com as etapas sequenciais, mas, mais frequentemente, novas descobertas, restrições e insights orientam à um processo cíclico, onde conceitos básicos devem ser revisitados consecutivamente (BROWN, 2010).

A mentalidade adotada neste processo orienta de forma otimista à experimentação, com o benefício de explorar e testar diversas possibilidades ao longo do caminho. No desenvolvimento do processo as ideias devem ser aplicadas e validadas de forma rápida, favorecendo o pensamento abdutivo, visual e holístico (HASSI e LAAKSO, 2011). 


\section{A contribuição dos processos colaborativos do design para a economia solidária}

Por meio das reflexões acerca das abordagens do design neste artigo, optamos por utilizar o termo design colaborativo/codesign em detrimento do termo design participativo, a partir desta etapa. Esta decisão reflete a compreensão de que a aplicação de um processo de design no meio econômico solidário deve incluir a colaboração ativa dos participantes, e que no processo do design participativo o conceito de colaboração não é, necessariamente, um imperativo.

Consideramos que os conceitos, métodos, práticas e estudos do design participativo contribuem imensamente para esta discussão. Nos posicionamos, portanto, em concordância com Manzini e Rizzo (2015, p.201), que propõem o design participativo "como uma atividade complexa do co-design".

Heemann, Lima e Corrêa $(2008$, p.5) discutem que o trabalho colaborativo no design engloba os conceitos de cooperação, compartilhamento e trabalho em equipe, de forma a atingir "uma profunda interação e fusão de valores que culminem na resolução conjunta de problemas". Qual seria, portanto, o papel e a conduta do designer em um processo projetual colaborativo dentro de empreendimentos econômicos solidários?

O processo de design colaborativo não se difere, necessariamente, da essência de etapas que se alternam no percurso entre a concepção de problemas e a solução de problemas, porém, a colaboração no design implica desafios particulares no processo aplicado, sendo a "criação de um entendimento compartilhado" (FONTANA et al., 2012, p.7) o desafio crucial a ser desenvolvido para o êxito das demais etapas do processo colaborativo.

Kleinsmann e Valkenburg (2008) definem co-design como um processo de criação de entendimento compartilhado sobre o processo de design e o conteúdo de design. A ausência do entendimento compartilhado leva à ciclos repetitivos no processo de design e reduz a qualidade do produto final. Este entendimento pode ser conquistado pelos integrantes por meio do diálogo, documentos textuais, aportes visuais e protótipos (KLEINSMANN, 2006).

A lógica da economia solidária pressupõe que todos os sócios de um empreendimento devem estar envolvidos nas mais diversas questões relacionadas ao estabelecimento, isso aconteceria durante reuniões e assembleias, de maneira que as tomadas de decisões possam ser conduzidas de forma democrática.

Desta maneira, torna-se evidente que em um processo de design colaborativo, não só os não-designers devem aspirar por conhecer o universo e a linguagem do design, o especialista também deverá compreender as características e a cultura do empreendimento, de forma que todos os participantes entrem em acordo sobre o conteúdo do processo.

O processo de design nesta situação torna-se mais complexo, visto que, supostamente, os integrantes de um empreendimento solidário não terão instruções formais em práticas projetuais, exigindo do designer uma maior sensibilidade na criação do entendimento compartilhado. Todavia, 
estes fatores podem levar à resultados positivos, por incorporar diferentes contextos e visões de mundo na resolução de um problema.

Sanders e Stapers $(2008$, p. 13) preveem que a colaboração no processo de design reunirá, cada vez mais, atores de diferentes "culturas disciplinares, empresariais, étnicas, etc.”. Desta forma, deverá haverá uma valorização de "novas linguagens que suportem e facilitem as muitas variedades de comunicações multiculturais".

As habilidades pessoais dos integrantes não-designers devem, portanto, ser incentivadas pelo designer atuante, que deve estimular processos criativos e dialógicos. $\mathrm{O}$ designer fornece conhecimentos especializados que os outros integrantes do processo colaborativo não possuem, como a habilidade de pensamento visual, domínio de processos criativos, maior capacidade de investigação do problema e de informações ausentes, conhecimento de tecnologias existentes e emergentes, e a visão do processo projetual com um todo. Neste sentido, a elucidação e aplicação das ferramentas e etapas propostas no design thinking pode ser percebida como uma metodologia eficiente. A transferência deste conhecimento de uma esfera abstrata para o domínio concreto dos não-designers torna-se, então, essencial para chegar ao entendimento compartilhado e atingir a colaboração no processo de design.

Os esforços colaborativos para o êxito dos processos dialógicos do conteúdo de design visam, principalmente, melhores resultados ao fim do projeto. Mas, ao contextualizar o caráter emancipatório que deve envolver as atividades da economia solidária e que pode também definir a atuação do design, compreendemos que a formulação de um processo adequado às competências singulares dos atores de um empreendimento revela-se tão importante quanto seus resultados.

\section{Conclusão}

A investigação acerca dos conceitos teóricos do Design Participativo, do Design Colaborativo e do Design Thinking nos elucida sobre as diversas dimensões que estas abordagens podem abranger. Podemos citar alguns pontos em comum entre as abordagens analisadas: o envolvimento do design com processos sociais; o processo de design enquanto um trabalho coletivo entre atores interdisciplinares; a comunicação e a criação de um entendimento compartilhado como fatores chave para a condução do processo de design.

Pensando tais abordagens aplicadas à lógica da economia solidária, acreditamos que a intervenção de um designer em empreendimentos solidários deve ocorrer mediante a identificação das demandas específicas do empreendimento e então, devem ser conduzidas oficinas de capacitação, onde os participantes possam adquirir conhecimentos práticos acerca do processo de design, ferramentas e métodos utilizados, com ênfase nas propostas do design thinking. 
O conjunto de habilidades específicas do designer, o colocam em uma posição central dentro de um processo colaborativo com não-designers. Neste processo, o designer pode atuar tanto como um facilitador ou como um provocador, que atua de forma estratégica, reunindo e expandindo as competências dos demais integrantes e direcionando as tomadas de decisões de acordo com as especificidades e demandas do projeto.

Assim, consideramos fundamental o estudo do design neste âmbito, com o intuito de desenvolver tanto a prática da economia solidária, quanto as técnicas do design colaborativo como uma alternativa sustentável para cadeia produtiva de bens de consumo.

Enxergamos a interligação entre a abordagem de Papanek, os valores da economia solidária e os princípios do design colaborativo como um potencial de uma transformação, contextualizada neste artigo. $O$ design colaborativo atuaria, de modo a viabilizar a proposta da economia solidária e, articular, de forma holística, o pensamento do design, as questões trabalhistas, sociais e ambientais no contexto produtivo atual.

\section{Referências}

BARBOSA, L. Sociedade de Consumo. Rio de Janeiro: Jorge Zahar Ed. , 2004

BONSIEPE, G. Design, Cultura e Sociedade. São Paulo: Blucher, 2011.

BROWN, T. Design Thinking: uma metodologia poderosa para decretar o fim das velhas ideias. Rio de Janeiro: Elsevier, 2010

CHIU, M. L. An organizational view of design communication in design collaboration. Design Studies, v.23, n.2, p.187-210, 2002.

COELHO, L. A. L. Conceitos-chave em design. Rio de Janeiro: PUC-Rio, 2008.

EHN, P. Participation in Design Things. In: PARTICIPATORY DESIGN CONFERENCE, 30 September-4 October, Bloomington. Proceedings... New York: ACM, 2008, p.92-102.

FONTANA, I. M.; HEEMANN, A.; FERREIRA, M. G. G. Fatores críticos de sucesso para a colaboração no design de sistemas produto-serviço. Design e Tecnologia, [S.1.], v. 2, n. 4, p. 5360, dez. 2012. Disponível em: <https://www.ufrgs.br/det/index.php/det/article/view/87>. Acesso em: 25 de janeiro 2018. doi: http://dx.doi.org/10.23972/det2012iss04pp53-60.

FUJITA, R. M. L. Economia solidária na indústria têxtil e de confecção: influência dos atributos relativos ao mito fundador na moda brasileira. 2017. $168 \mathrm{f}$. Dissertação (Mestrado em Têxtil e Moda) Escola de Artes, Ciências e Humanidades, Universidade de São Paulo, 2017.

GAIGER, L. A economia solidária diante do modo de produção capitalista. Caderno CRH, Salvador, v. 16, n. 39, p. 181-211, 2003. Disponível em: <http://www.cadernocrh.ufba.br/viewissue.php?id=12>. Acesso em: 10 de março 2018.

HEEMANN, A.; LIMA, P. J. V.; CORRÊA, J. S. Fundamentos para o Alcance da Colaboração em Design. In: CONGRESSO BRASILEIRO DE PESQUISA E DESENVOLVIMENTO EM DESIGN, 8, São Paulo, 2008. Anais...São Paulo: Senac, 2008.

JESUS, P.; TIRIBA, L. Cooperação. In: CATTANI et al. Dicionário Internacional da Outra Economia. São Paulo: Almedina, p.80-85, 2009.

KLEINSMANN, M. S. Understating collaborative design. Ph.D. thesis, Delft University of Technology. Delft, 2006. 
KLEINSMANN, M.; VALKENBURG, R. Barriers and enablers for creating shared understanding in co- design projects. Design Studies, v. 29, n. 4, p. 369-386, 2008.

LAVILLE, J. L. Solidariedade. In: CATTANI et al. Dicionário Internacional da Outra Economia. São Paulo: Almedina, p.310-314, 2009.

LAVILLE, J. L.; GAIGER, L. I. Economia Solidária. In: CATTANI et al. Dicionário Internacional da Outra Economia. São Paulo: Almedina, p.162-168, 2009.

LEE, Y. Design participation tactics: the challenges and new roles for designers in the co-design process. CoDesign, v.4, n.1, p. 31-50, 2008.

MANZINI, E. Design Para a Inovação Social e Sustentabilidade: comunidades criativas, organizações colaborativas e novas redes projetuais. Rio de Janeiro: E-papers, 2008.

MANZINI, E.; RIZZO, F. Small projects/large changes: Participatory design as an open participated process. CoDesign, v. 7, n. 3-4, p.199-215, 2011.

PANTALEÃO, L. F.; PINHEIRO, O.J; MENEZES, M.F. Teoria e prática, ética e estética no design de produtos: questões de sustentabilidade como alternativa para subversão da atual cultura material de consumo. In: CIMODE - Congresso Internacional de Moda e Design, 3, Buenos Aires, 2016.

PAPANEK, V. Arquitectura e design, ecologia e ética. Lisboa: Edições 70, 1995.

ROBERTSON, T.; SIMONSEN, J. Participatory Design: An introduction. In: ROBERTSON, T.; SIMONSEN, J. (Eds.). . Routledge International Handbook of Participatory Design. 1. ed. New York: Routledge, p. 1-18, 2013.

SANDERS, E. B.-N.; STAPPERS, P. J. Co-creation and the new landscapes of design. CoDesign, V. 4, n. 1, 2008.

SANDERS, E. B. N., BRANDT, E., BINDER, T. Framework for Organizing the Tools and Techniques of Participatory Design. Proceedings of Participatory Design Conference 2010, Sydney, Australia. 2010

SINGER, P. Introdução à economia solidária. São Paulo: Editora Fundação Perseu Abramo, 1a ed, 2002.

VENDRAMINI, L. C., HEEMANN, A. Design colaborativo: categorias de colaboração e implicações na comunicação. In: Gampi Plural, 5, Joinville, 2015. 